\title{
AN EXPERIMENTAL STUDY OF WAVE FORCES ON VERTICAL BREAKWATER
}

\author{
Yung-Fang Chiu \\ Center of Harbor and Marine Technology, Institute of Transportation, Taiwan. \\ Jaw-Guei Lin

\section{Shang-Chun Chang} \\ Department of Harbor and River Engineering, National Taiwan Ocean University. \\ Yin-Jei Lin \\ Department of Harbor and River Engineering, National Taiwan Ocean University. \\ Chia-Hsin Chen \\ Department of Harbor and River Engineering, National Taiwan Ocean University.
}

Department of Harbor and River Engineering, National Taiwan Ocean University., jglin@mail.ntou.edu.tw

Follow this and additional works at: https://jmstt.ntou.edu.tw/journal

Part of the Civil and Environmental Engineering Commons

\section{Recommended Citation}

Chiu, Yung-Fang; Lin, Jaw-Guei; Chang, Shang-Chun; Lin, Yin-Jei; and Chen, Chia-Hsin (2007) "AN EXPERIMENTAL STUDY OF WAVE FORCES ON VERTICAL BREAKWATER," Journal of Marine Science and Technology. Vol. 15: Iss. 3, Article 2.

DOI: $10.51400 / 2709-6998.2390$

Available at: https://jmstt.ntou.edu.tw/journal/vol15/iss3/2

This Research Article is brought to you for free and open access by Journal of Marine Science and Technology. It has been accepted for inclusion in Journal of Marine Science and Technology by an authorized editor of Journal of Marine Science and Technology. 


\title{
AN EXPERIMENTAL STUDY OF WAVE FORCES ON VERTICAL BREAKWATER
}

\author{
Yung-Fang Chiu*, Jaw-Guei Lin**, Shang-Chun Chang**, \\ Yin-Jei Lin**, and Chia-Hsin Chen**
}

Key words: vertical breakwater, wave force, hydraulic model test.

\begin{abstract}
In this study, a series of hydraulic model tests with regular/ irregular waves was carried out in a wave flume to investigate the wave forces acting on a composite-type breakwater. Waves in front of the breakwater, wave pressures on the vertical wall and at the bottom of caisson were measured simultaneously. The maximum horizontal force and uplift force were calculated and compared with Goda's wave force theories. The results had shown that Goda's theories offer higher safety factor. However, the measured uplift force was smaller than Goda's and nonzero at the land-side end of the bottom which might be caused by the path of water flow in the porous media beneath the caisson. It also shows that the results from different irregular wave train with the same spectrum are different, and thus the effectiveness of conventional irregular wave tests with several repeats of the same wave train should be reconfirmed.
\end{abstract}

\section{INTRODUCTION}

Composite-type breakwater is the most popular structure for the harbors around Taiwan coast. However, due to the characteristic of Taiwan coast, most of them are constructed on sandy seabed, especially at Taiwan West Coast. Vertical caisson, large wave force and sandy seabed create a very sensitive circumstance that several kinds of structure failure might occur. From previous relevant studies, such as Oumeraci [8] and Coastal Engineering Manual by U. S. Army Corps of Engineering [13], the causes of structure failure can be classified into three types: (1) the material strength destruction or the mechanical instability of the structure, (2) the exceptional hydraulic conditions including extreme wave force or excess water level, and (3) the foundation or the seabed instabilities including the scouring and the settlement. However, except for all these

Paper Submitted 05/22/06, Accepted 08/09/06. Author for Correspondence: J.G.Lin.E-mail: jglin@mail.ntou.edu.tw.

*Center of Harbor and Marine Technology, Institute of Transportation, Taiwan.

**Department of Harbor and River Engineering, National Taiwan Ocean University. individual failure mechanisms, the dynamic behavior of a Composite-type breakwater under the interaction among waves, vertical caisson, rubber mound foundation and sandy seabed, might also be the cause of structure failure.

Three different types of wave force acting on the vertical breakwater are identified: non-breaking waves, breaking waves with almost vertical front, and breaking waves with large air pockets, and therefore hydraulic model tests performed in the final stage of the coastal structure design become a common sense and a necessary step [3]. Several wave force theories have been promoted for the evaluation of the wave force acting on vertical wall. For example, under the assumption of uniformly distributed loads with averaged wave pressure acting on vertical wall, Hiroi, in 1920, proposed the first wave pressure formula. Sainflou, in 1928 , theoretically derived a simple form of standing wave force formula. In 1950, Minikin formula was proposed from the studies of impact force tests. Based on the Ito's continuous loading and maximum wave height concepts, and the experimental/field data, Goda, in 1973, obtained four equations for the design load on vertical walls and becomes the most popular equations in the recent coastal structure design. The equations are shown as follow, and the related sketch is shown in Figure 1.

$$
\begin{aligned}
& \eta^{*}=0.75(1+\cos \beta) H_{\max } \\
& P_{1}=0.5(1+\cos \beta)\left(\alpha_{1}+\alpha_{2} \cos ^{2} \beta\right) \rho \mathrm{g} H_{\max } \\
& P_{2}=\frac{1}{\cosh (2 \pi h / L)} \\
& P_{3}=\alpha_{3} P_{1} \\
& P_{u}=0.5(1+\cos \beta) \alpha_{1} \alpha_{3} \rho \mathrm{g} H_{\max }
\end{aligned}
$$

where, $\beta$ is incident wave angle; $H_{\max }$ is the maximum wave height in the design sea state at the location just in front of the breakwater; $L$ is wave length; $h$ is the wave depth at a distance of $5 H_{s}$ seaward of the breakwater 


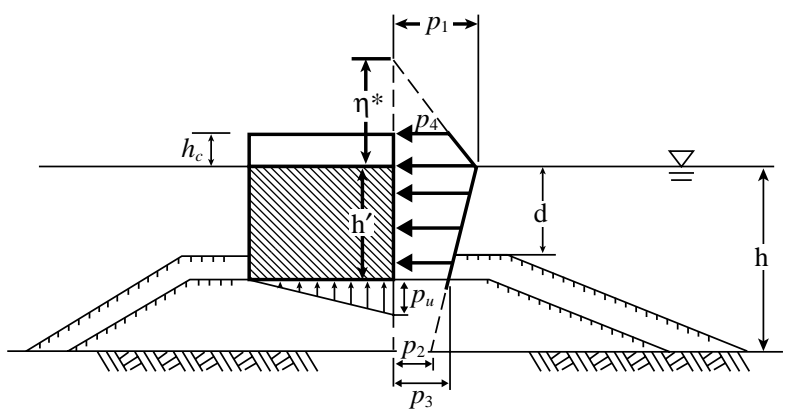

Fig. 1. Goda's wave force distribution.

front wall; $H_{s}$ is the significant wave height;

$$
\begin{aligned}
& \alpha_{1}=0.6+0.5\left[\frac{4 \pi h / L}{\sinh (4 \pi h / L)}\right]^{2} ; \\
& \alpha_{2}=\min \left\{\frac{h_{b}-d}{3 h_{b}}\left(\frac{H_{\max }}{d}\right)^{2}, \frac{2 d}{H_{\max }}\right\} ; \\
& \alpha_{3}=1-\frac{h^{*}}{h}\left[1-\frac{1}{\cosh (2 \pi h / L)}\right]
\end{aligned}
$$

On account of the complexity of wave behavior in front of a vertical breakwater, the evaluation of wave forces on vertical breakwater are mostly done by hydraulic experiment in a wave flume. For example, Oumeraci et al. [11], Schmidit et al. [12], Oumeraci and Kortenhaus [9], Hattori et al. [4], Klammer [5], Kortenhaus and Oumeraci [6], Oumeraci et al. [10]. Regular/irregular wave trains are usually selected as incident waves. Regular wave tests employed the representative wave height/period of incident waves, but irregular wave tests employed their spectrum. In order to retain the statistical accuracy, the experiments are always repeated at least three times in both regular/ irregular wave tests. Due to the randomness of practical waves, however, the wave trains with the same spectrum are always different. So, not only the results obtained from regular/irregular wave experiments are different, but also the results from each irregular wave tests with different wave train from the same spectrum are different. Such phenomenon leads to the suitability investigation of regular/irregular wave experiments.

In this paper, the experimental data from a series of regular/irregular hydraulic model tests of a composite-type breakwater deployed on a sandy seabed, carried out by Center of Harbor and Marine Technology, Institute of Transportation (hereafter, IHMT) and Department of Harbor and River Engineering, National Taiwan Ocean University (hereafter, NTOU), were used to investigate the wave forces on the caisson. Full discussions of the experiments can be found in Chen [1] and Lin [7].

\section{EXPERIMENTAL SETUP}

The experiments were carried out in the wave flume (see Figure 2), which is located in Wind Tunnel Laboratory, IHMT. A composite-type breakwater (see Figure 3) was built on a sandy seabed (see Figure 4) in the wave flume.

As shown in Figure 4, the wave flume is $100 \mathrm{~m}$ long, $1.5 \mathrm{~m}$ wide and $2.0 \mathrm{~m}$ high with piston type wave maker. The system can generate regular waves and irregular waves with JONSWAP and Bretschneider spectra. The suggested wave frequency range is between $0.2 \mathrm{~Hz}$ and $2 \mathrm{~Hz}$, the experimental suggested

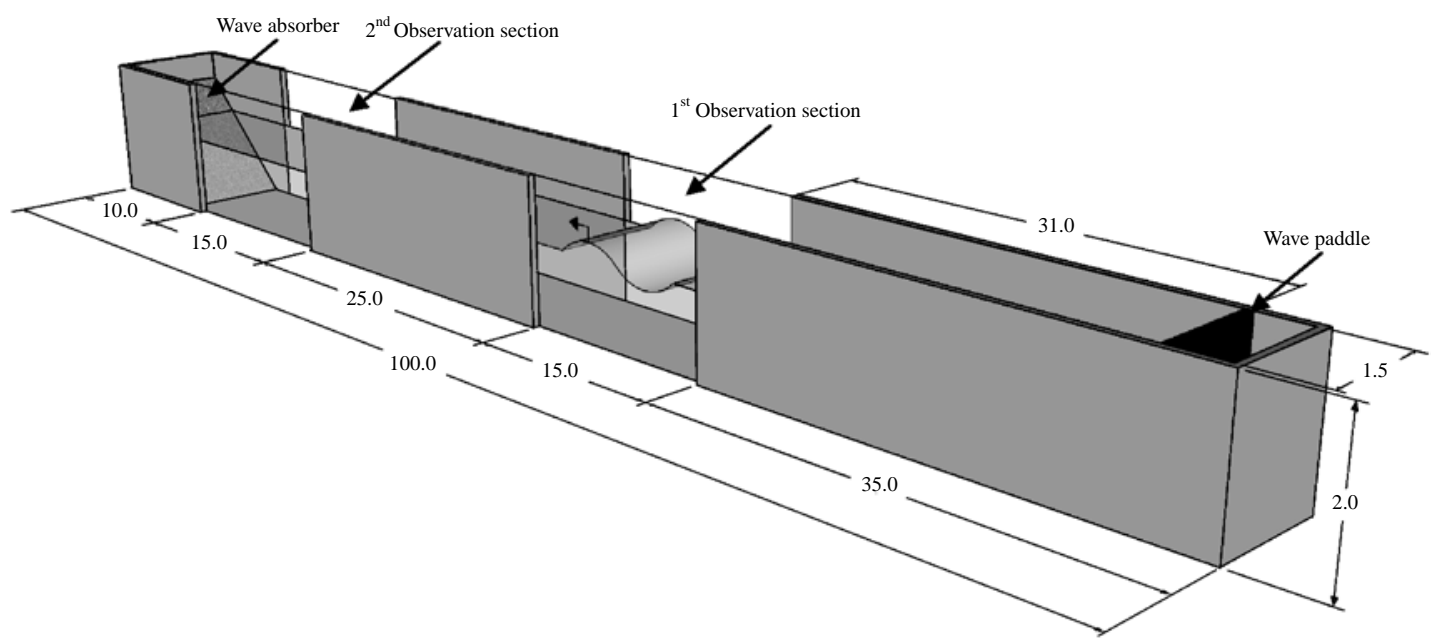

Fig. 2. Layout of experimental wave flume (unit: m). 


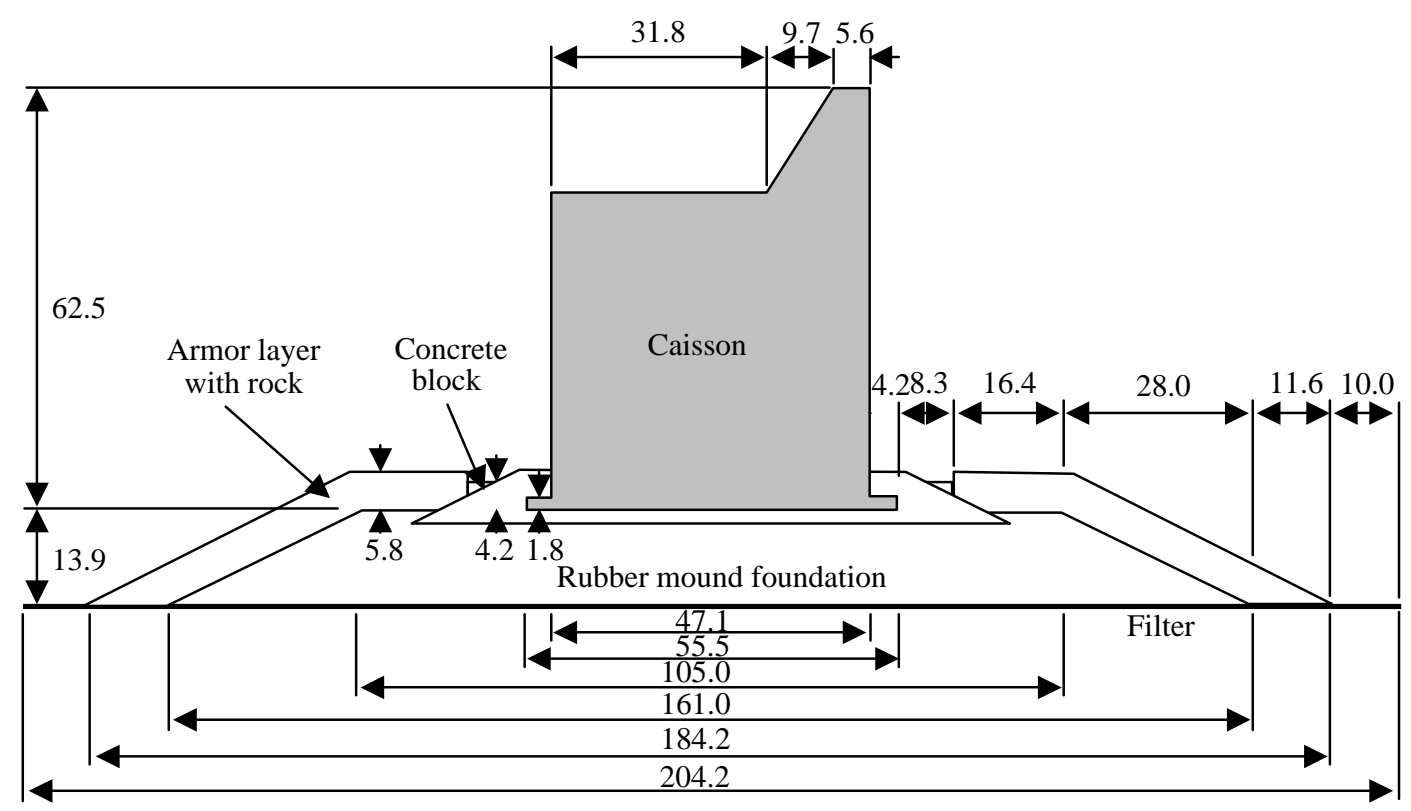

Fig. 3. Layout of the breakwater (scale 1:36, unit: cm)

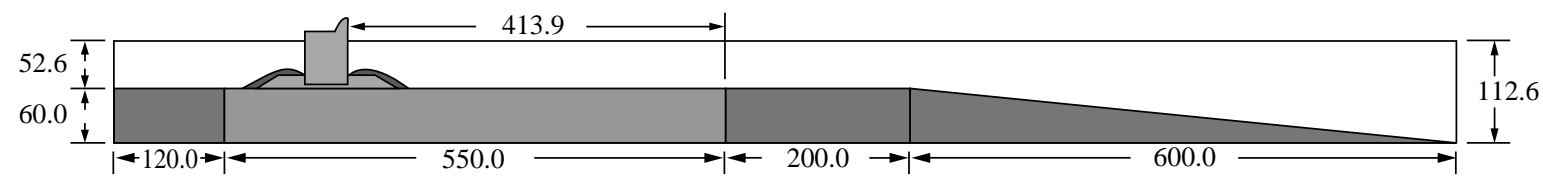

Fig. 4. Experimental setup (unit: $\mathrm{cm}$ )

Table 1. Experimental regular wave cases (Case ID in parentheses)

\begin{tabular}{ccccc}
\hline Wave height $\mathrm{H}(\mathrm{cm})$ & 8.33 & 13.89 & 19.44 & 25.00 \\
Wave period $\mathrm{T}(\mathrm{s})$ & & & & \\
\hline 1.00 & $\sqrt{ }(\mathrm{H} 08 \mathrm{~T} 10)$ & & \\
1.33 & $\sqrt{ }(\mathrm{H} 08 \mathrm{~T} 13)$ & $\sqrt{ }(\mathrm{H} 13 \mathrm{~T} 13)$ & & \\
1.67 & $\sqrt{ }(\mathrm{H} 08 \mathrm{~T} 16)$ & $\sqrt{ }(\mathrm{H} 13 \mathrm{~T} 16)$ & $\sqrt{ }(\mathrm{H} 19 \mathrm{~T} 16)$ & \\
2.00 & $\sqrt{ }(\mathrm{H} 08 \mathrm{~T} 20)$ & $\sqrt{ }(\mathrm{H} 13 \mathrm{~T} 20)$ & $\sqrt{ }(\mathrm{H} 19 \mathrm{~T} 20)$ & $\sqrt{ }(\mathrm{H} 25 \mathrm{~T} 20)$ \\
\hline Remarks & 7 repeats without breakwater; 7 repeats with breakwater & \\
\hline
\end{tabular}

water depth is $1 \mathrm{~m}$ and the maximum wave height is $0.32 \mathrm{~m}$.

The model scale of the experiments is $1: 36$. In order to simulate the nearshore waves in front of the breakwater (see Figure 4), the seabed was combined with one 1:10 sloping bottom with $6 \mathrm{~m}$ long to change the water depth from $1.126 \mathrm{~m}$ to $0.526 \mathrm{~m}$, a fixed horizontal seabed with $2 \mathrm{~m}$ long, a sand trench with 5.5 $\mathrm{m}$ long and $0.6 \mathrm{~m}$ deep, and a $1.2 \mathrm{~m}$ long fixed bed behind the breakwater to maintain the trench. The water depth in front of the breakwater is $0.526 \mathrm{~m}$, and the caisson was set at the distance of $4.139 \mathrm{~m}$ measured from the front edge of the sand trench. According to the model scale, the offshore water depth $(1.126 \mathrm{~m})$ is around $40 \mathrm{~m}$ in practice.

Two incident wave types are carried out in the experiments. Table 1 shows ten regular wave cases tested in the experiments, the parentheses show their case ID numbers. The maximum wave height was chosen to avoid the wave breaking. The irregular wave cases introduced the representative waves shown in Table 1 as significant wave height $\left(\mathrm{H}_{1 / 3}\right)$ and related period $\left(\mathrm{T}_{1 / 3}\right)$ into JONSWAP spectrum [2] shown as follow 


$$
\begin{aligned}
S(f) & =\beta_{J} H_{1 / 3}^{2} T_{P}^{4} f^{-5} \exp \left[-1.25\left(T_{p} f\right)^{-4}\right] \\
& \cdot \gamma^{\exp \left[-\left(T_{p} f-1\right)^{-2} / 2 \sigma^{2}\right]}
\end{aligned}
$$

where

$$
\beta_{J} \cong \frac{0.0624}{0.230+0.0336 \gamma-0.185(1.9+\gamma)^{-1}}[1.094-0.01915 \ln \gamma]
$$

$$
T_{p} \cong T_{1 / 3} /\left[1-0.132(\gamma+0.2)^{-0.559}\right]
$$

In order to take into account the phase change effects of each component waves in the irregular wave train, each spectrum were generated three wave trains according to different random phases. Table 2 shows the irregular wave cases, each wave train was repeated twice for the cases with breakwater, and once for the cases without breakwater.

By considering the damping effect of sandy seabed, the incident waves at different locations were firstly measured before the breakwater was deployed. A capacitance wave gauge was set right on the location of the breakwater, and 7 repeats for all 10 regular wave cases and one run with 3 wave trains for all 4 irregular wave cases were tested. After the breakwater was set on

Table 2. Experimental irregular wave cases

\begin{tabular}{lcccc}
\hline Wave cases & $\mathbf{1}$ & $\mathbf{2}$ & $\mathbf{3}$ & $\mathbf{4}$ \\
\hline $\mathrm{f}_{\mathrm{p}}(\mathrm{Hz})$ & 0.928 & 0.698 & 0.556 & 0.464 \\
$\mathrm{H}_{1 / 3}(\mathrm{~cm})$ & 8.33 & 13.89 & 19.44 & 25.00 \\
$\mathrm{~T}_{1 / 3}(\mathrm{sec})$ & 1.00 & 1.33 & 1.67 & 2.00 \\
Wave trains & JH08T10-1 & JH13T13-1 & JH19T16-1 & JH25T20-1 \\
(case ID) & JH08T10-2 & JH13T13-2 & JH19T16-2 & JH25T20-2 \\
& JH08T10-3 & JH13T13-3 & JH19T16-3 & JH25T20-3 \\
\hline Remarks & 1 without breakwater; 2 repeats with breakwater \\
\hline
\end{tabular}

the seabed, 7 repeats for all regular wave cases and 2 repeats of for all irregular wave cases with 3 wave trains were executed.

For the measurements of wave pressure on the breakwater, 5 pressure gauges along the sea-side vertical wall of the caisson for horizontal pressures and 4 pressure gauges on the bottom of the caisson for uplift pressures were deployed. Figure 5 shows their locations, and the pressure gauges were labeled respectively as V1 $\sim$ V5 from top to toe along the vertical wall, and U1 U4 from right to left along the caisson bottom for the following discussions. The locations of $\mathrm{V} 1$ and $\mathrm{V} 2$ are adjustable according to the wave case to be tested, the dimensions marked at the left side of vertical wall in Figure 5 are the locations of pressure gauges used in regular wave cases with $\mathrm{H}=8.33 \mathrm{~cm}$ and $13.89 \mathrm{~cm}$, and the dimensions marked at the right side of the vertical wall are the locations of pressure gauges used in regular wave cases with $\mathrm{H}=19.44 \mathrm{~cm}$ and $25 \mathrm{~cm}$ and in irregular wave cases. The waves and pressures were all sampled with $20 \mathrm{~Hz}$ rate for 90 seconds in each test.

The time series of wave profiles and pressure profiles are analyzed by means of zero-up-crossing method after de-mean and de-trend processes. Wave forces acting on the breakwater are calculated from the distributions of wave pressures with following equations (see Figure 6). The pressures at two ends of the vertical wall and of the caisson bottom were linearly extrapolated from the measured data.

$$
\begin{aligned}
& \text { Total horizontal force } \mathrm{F}_{\mathrm{H}}=\sum_{i=1}^{13} \text { Area }_{i} \\
& \text { Total uplift force } \mathrm{F}_{\mathrm{U}}=\sum_{i=14}^{23} \text { Area }_{i}
\end{aligned}
$$

Acting location of total horizontal force

$$
\bar{X}=\frac{\sum_{i=1}^{13} \text { Area }_{i} * X_{i}}{F_{H}}
$$

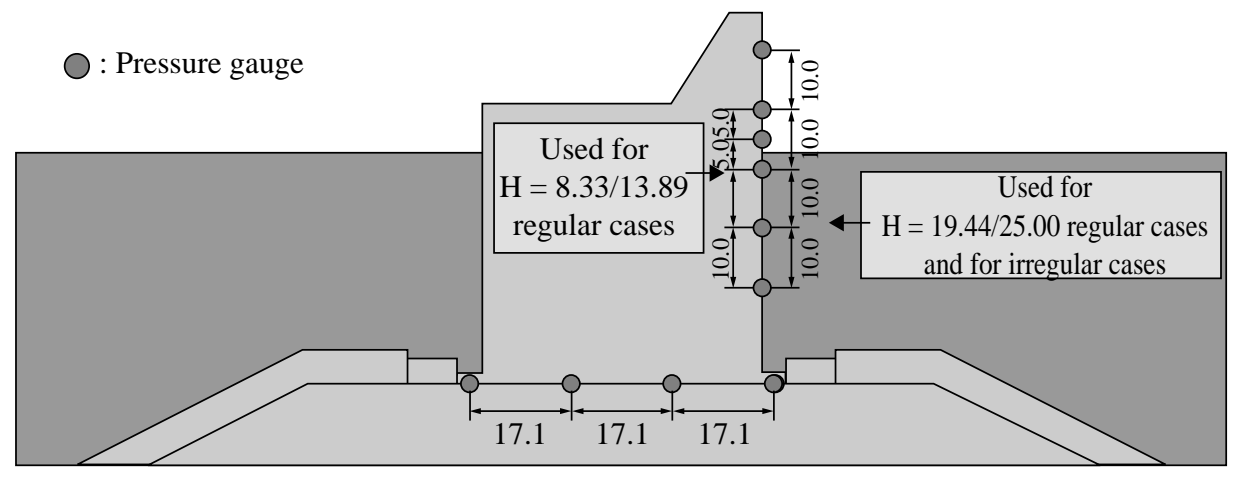

Fig. 5. Locations of pressure gauges (unit: $\mathrm{cm}$ ) 
Acting location of total uplift force

$$
\bar{Y}=\frac{\sum_{i=14}^{23} \operatorname{Area}_{i} * Y_{i}}{F_{U}}
$$

where

$X_{i}(i=1 \sim 13)$ : The horizontal distance of the centroid of Area $_{i}$ from origin

$Y_{i}(i=14 \sim 23)$ : The vertical distance of the centroid of Area $_{i}$ from origin

\section{EXPERIMENTAL RESULTS}

The discussions of the experimental results are divided into two parts: regular waves and irregular waves, and then the comparisons are presented.

\section{Regular wave results}

Table 3 shows the wave heights/periods measured at deep water zone as incident waves and at the location

Table 3. Measured Progressive waves

\begin{tabular}{lrrrc}
\hline \multirow{2}{*}{ Case ID } & \multicolumn{2}{c}{ Incident waves } & \multicolumn{2}{c}{ Waves at breakwater } \\
\cline { 2 - 5 } & \multicolumn{1}{c}{$\mathrm{H}_{\mathrm{o}}(\mathrm{cm})$} & $\mathrm{T}_{\mathrm{o}}(\mathrm{s})$ & $\mathrm{H}_{1 / 3}(\mathrm{~cm})$ & $\mathrm{H}_{\text {mean }}(\mathrm{cm})$ \\
\hline $\mathrm{H} 08 \mathrm{~T} 10$ & 8.33 & 1.00 & 8.15 & 6.42 \\
$\mathrm{H} 08 \mathrm{~T} 13$ & 8.33 & 1.33 & 8.66 & 8.50 \\
$\mathrm{H} 08 \mathrm{~T} 16$ & 13.89 & 1.33 & 6.89 & 6.73 \\
$\mathrm{H} 08 \mathrm{~T} 20$ & 8.33 & 1.67 & 9.58 & 9.21 \\
$\mathrm{H} 13 \mathrm{~T} 13$ & 13.89 & 1.67 & 14.69 & 14.33 \\
$\mathrm{H} 13 \mathrm{~T} 16$ & 19.44 & 1.67 & 11.26 & 10.97 \\
$\mathrm{H} 13 \mathrm{~T} 20$ & 8.33 & 2.00 & 15.27 & 15.01 \\
$\mathrm{H} 19 \mathrm{~T} 16$ & 13.89 & 2.00 & 15.28 & 14.62 \\
$\mathrm{H} 19 \mathrm{~T} 20$ & 19.44 & 2.00 & 21.30 & 20.55 \\
$\mathrm{H} 25 \mathrm{~T} 20$ & 25.00 & 2.00 & 25.17 & 23.97 \\
\hline
\end{tabular}

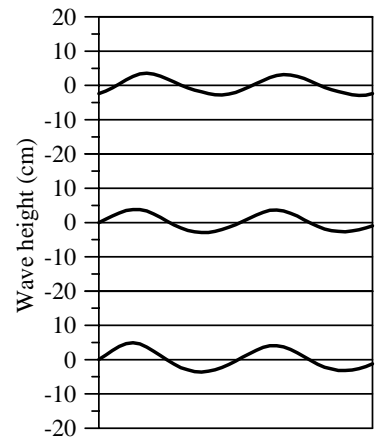

(a) CaseH08T10

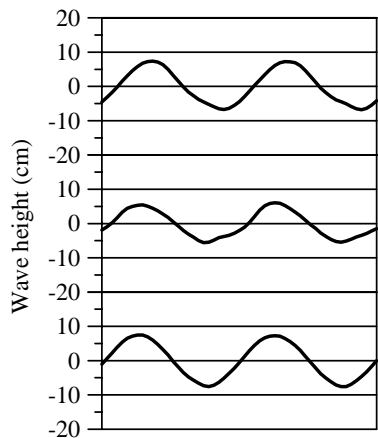

(b) Case H13T13

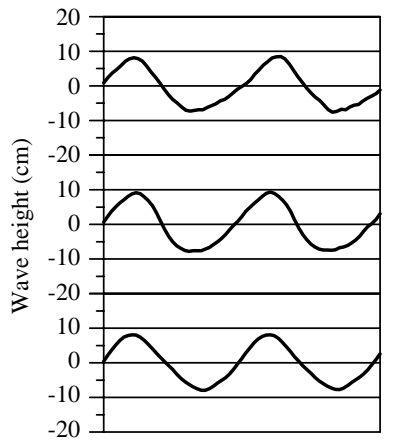

(c) Case H19T16

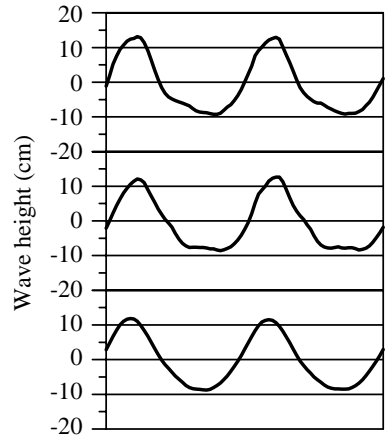

(d) Case H25T20

Fig. 7. Wave profiles at the location of breakwater in regular wave experiments. 
From Goda's theories, the variations of horizontal/uplift wave forces are directly proportioned to wave height and wave period, and the horizontal wave pressure and uplift wave pressure are equal at the sea-side toe of the caisson. Figures 9 and 10 present the relations between the maximum horizontal/uplift wave pressures and wave heights/periods from Case H25T20

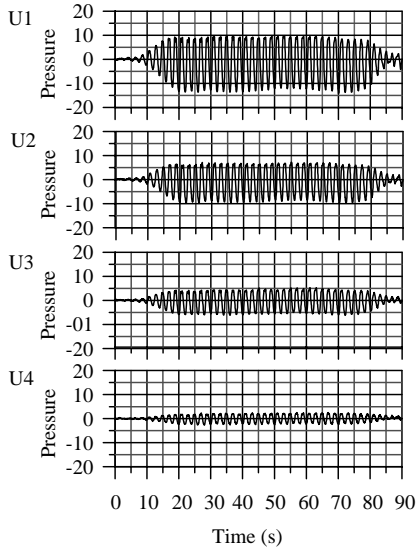

(a) At the bottom

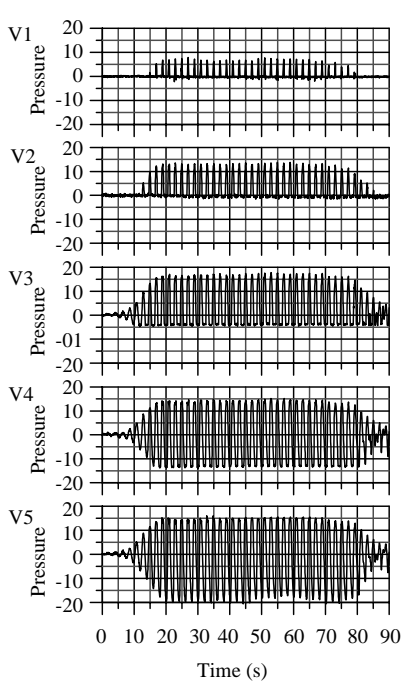

(b) On the vertical wall
Fig. 8. Time series of wave pressures on caisson (Case H25T20, pressure unit: $\mathbf{g f} / \mathrm{cm}^{2}$ ).
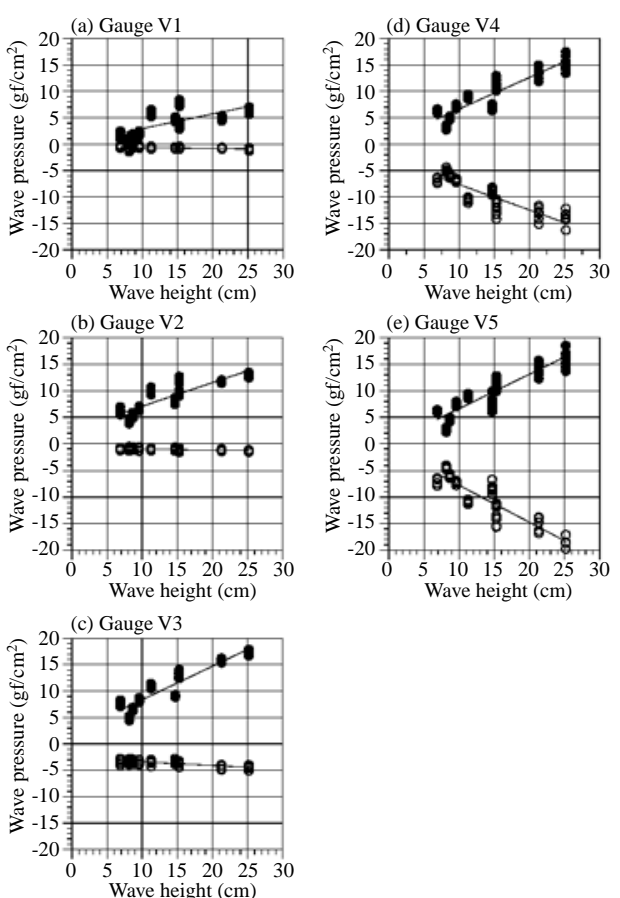

(a) Wave height respectively. The solid/hollow circles in the figures are respectively the maximum and minimum wave pressures, linear regression curves are also included. Linear and proportional relations can be found between wave pressures and wave height/period.

By comparing the V5 pressures in Figure 9 and U4 pressures in Figure 10, one can find that the pressures at the toe of the vertical wall appear to be larger than the pressures at the sea-side end of the bottom, which is different from Goda's theories that assuming to be equal. Furthermore, the non-zero pressures at the landside end of the caisson bottom are also different from Goda's. Such phenomena might be caused by the existence of footing of the caisson and porosity of the rubber mound foundation that change the flow pattern in the foundation.

Figure 11 shows the comparisons of wave forces on caisson. Linear regressions of measured and theoretical horizontal/uplift forces vs. wave heights are plotted. The measured horizontal/uplift forces are all smaller than Goda's wave forces, and the larger the wave height, that larger the difference.

From the observations on the time series of wave forces and profiles, the occurrence times of maximum/ minimum horizontal forces are found not consistent with the arrival of wave crest/trough. Such phenomenon causes the discussions on the definition of maximum wave force. Figure 12 shows the horizontal and the uplift forces calculated as wave peaks (crest/trough)
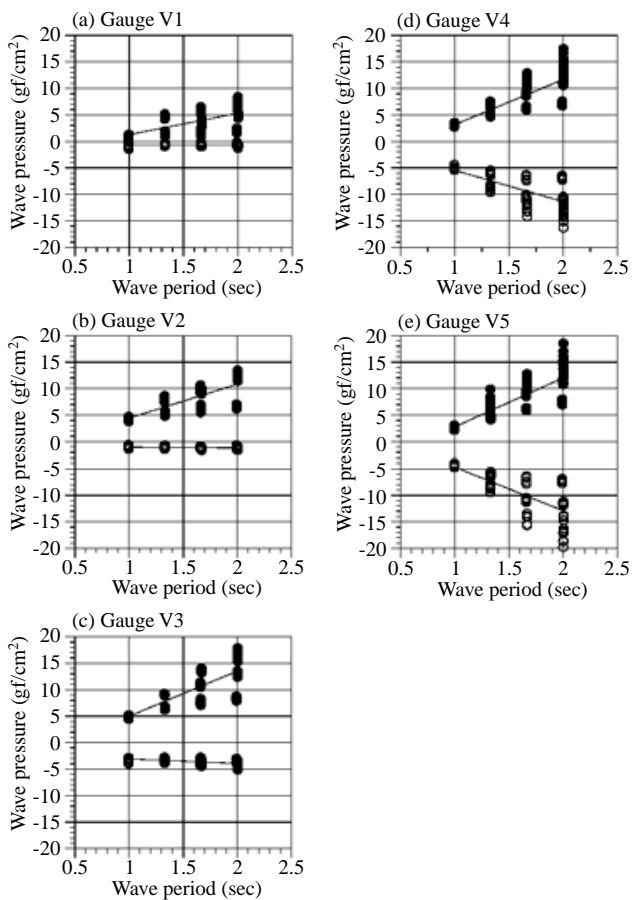

(b) Wave period

Fig. 9. Relations between wave height and maximum horizontal wave pressures (Case H25T20). 

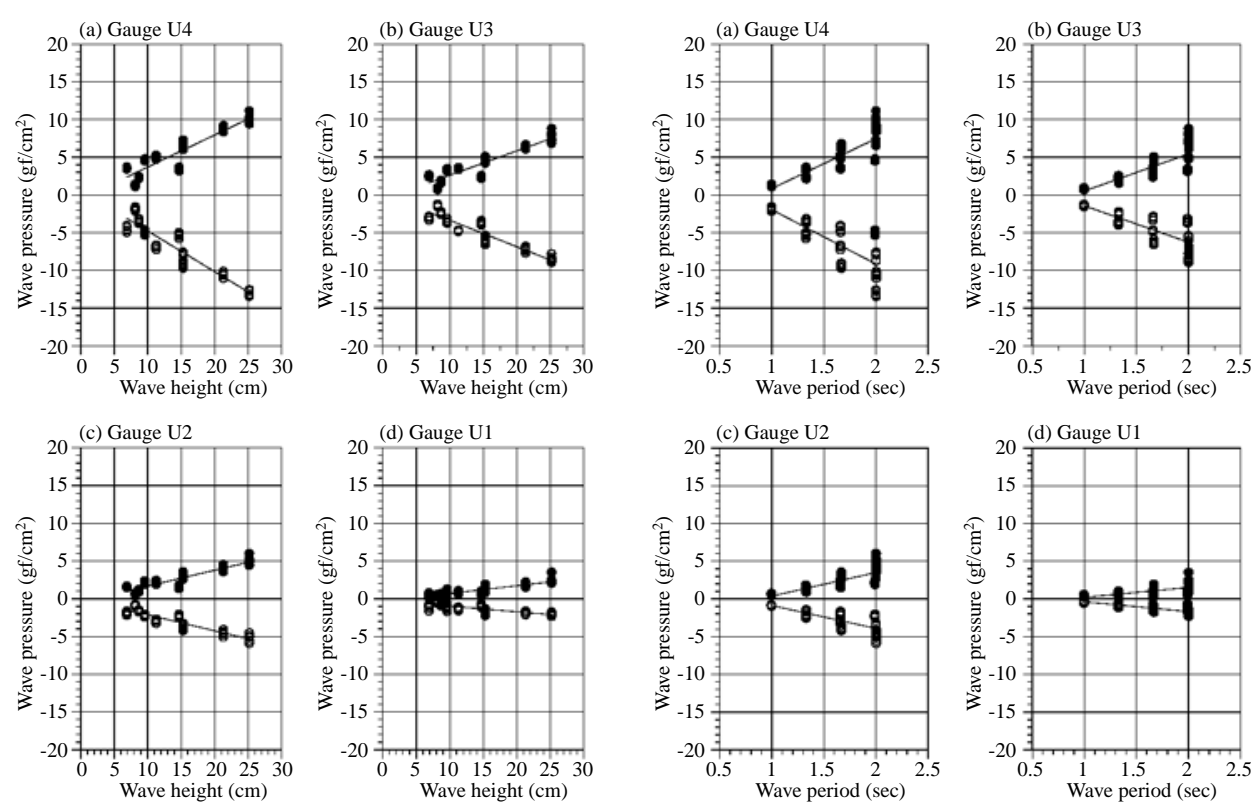

(a) Wave height
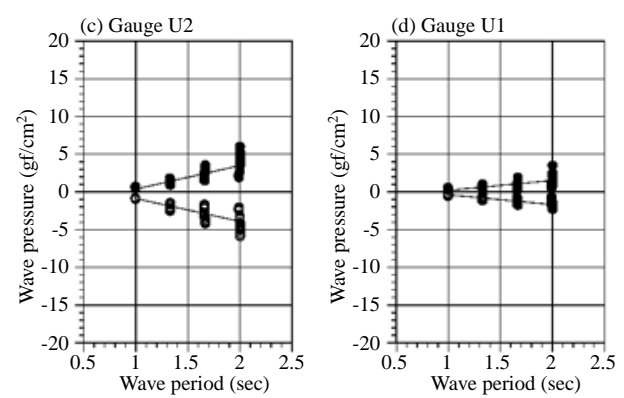

(b) Wave period

Fig. 10. Relations between wave height and maximum uplift wave pressures (Case H25T20).

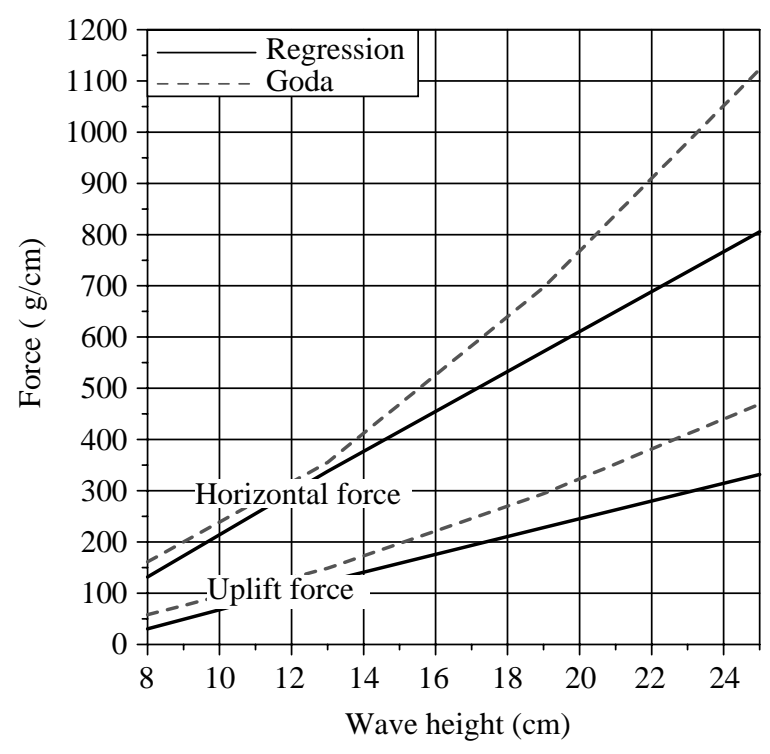

Fig. 11. Comparisons of wave forces on the caisson.

actions, the wave pressures at these moments might not be the largest. Figure 13 shows the horizontal and the uplift forces calculated from maximum/minimum wave pressures of all wave gauges. Linear regression curves are also included in Figures 12 and 13. Figure 14 collects their regression curves and shows there are a slightly difference between them, especially on the horizontal force. For convenient use in engineering design, wave forces at wave crest action with a proper safety factor are suggested.
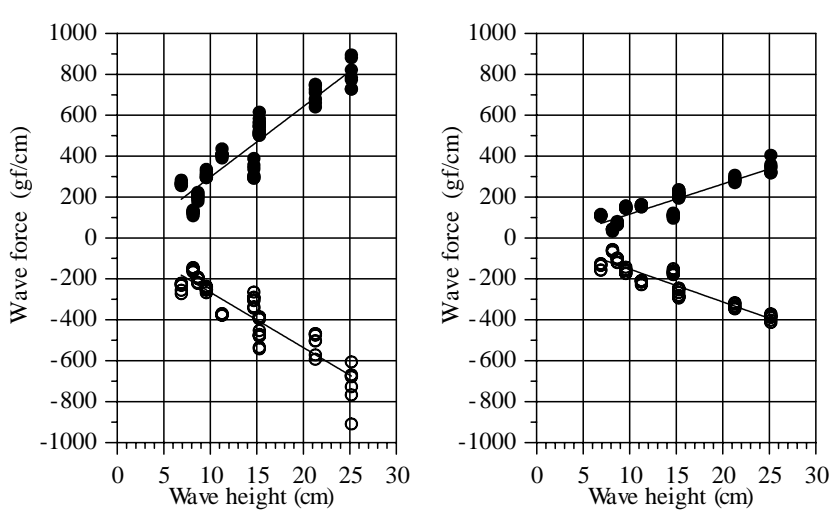

(a) Horizontal force at wave peak/trough

(b) Uplift force at wave peak/trough

Fig. 12. Maximum horizontal and uplift forces (calculated at wave crest/trough).

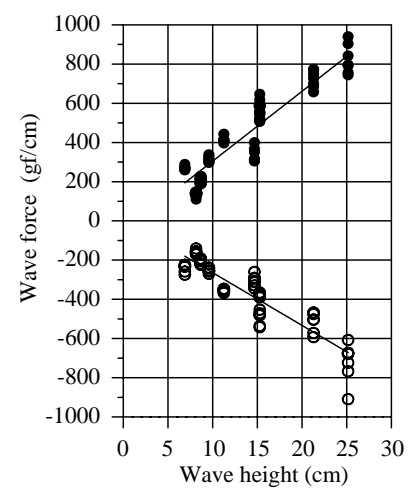

(a) Horizontal force at $\mathrm{P}_{\max } / \mathrm{P}_{\min }$

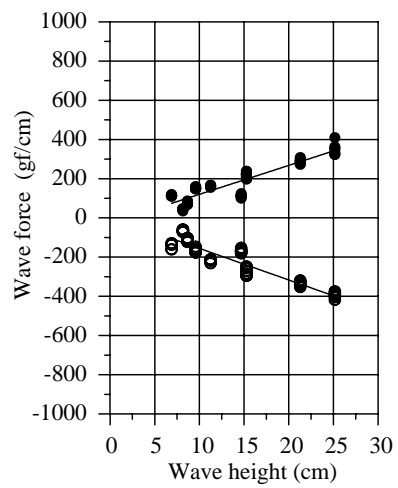

(b) Uplift force at $P_{\max } / P_{\min }$
Fig. 13. Maximum horizontal and uplift forces (calculated from all maximum pressures). 


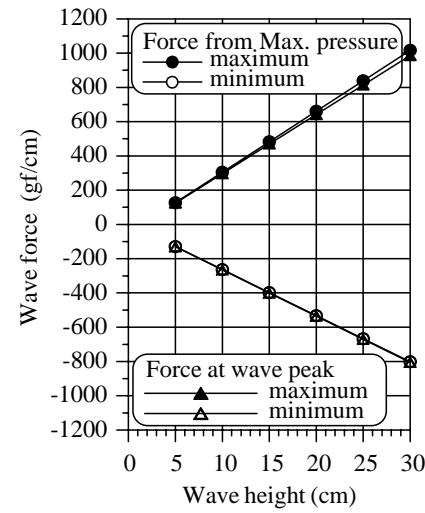

(a) Horizontal Force

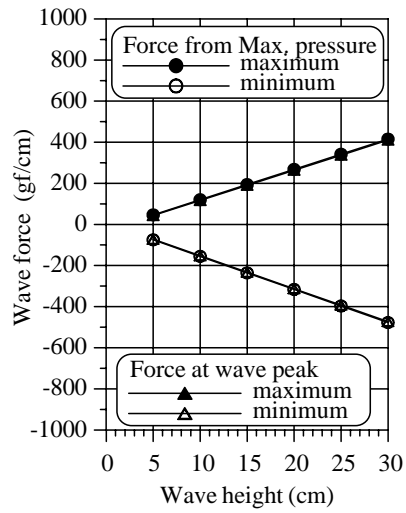

(b) Uplift Force
Fig. 14. Comparisons of wave forces calculated from wave crest and maximum pressures.

\section{Irregular wave results}

This study also investigates the irregular wave forces acting on the caisson. As mentioned above, JONSWAP spectra for four different wave conditions are selected and combined with three different phase sets of component waves to generate the wave trains in the experiments. Totally, 12 wave trains are used in this investigation, and each wave train is repeated twice for the cases with breakwater (standing wave cases), and once for the cases without breakwater (progressive wave cases). Figure 15 shows the relations of characteristic wave heights and related wave periods, and the ratio of $H_{1 / 3} / \sqrt{m_{0}}$ vs. $\mathrm{T}_{1 / 3}$ of the irregular progressive waves measured at the location of the breakwater. The figures show that different wave train may induce different maximum wave height and period, thus, it causes different wave forces acting on the breakwater; however, for significant wave height/period and for mean wave height/period, three different wave trains only cause a slightly difference with the maximum of $8 \%$ in wave height and the maximum of $5 \%$ in wave period. The ratio of $H_{1 / 3} / \sqrt{m_{0}}$ is also not a constant and lies between 3.7 and 4.0. From the investigation, one can find that different wave trains with the same spectrum and different component wave phases contain different wave characters.

Figure 16 shows the characteristic standing wave heights/periods in front of caisson. $\mathrm{H}_{\max }, \mathrm{H}_{1 / 10}$, and $\mathrm{H}_{1 / 3}$ of all irregular wave cases with two repeats are presented. Due to the random property of waves and of the interactions among waves, sandy seabed, rubber mound foundation and vertical breakwater, Figure 16 shows that, even using the same wave train, the wave height/period measured from two repeat tests are still not equal, not to mention the results from three different wave trains with the same spectrum. Again, the inves-
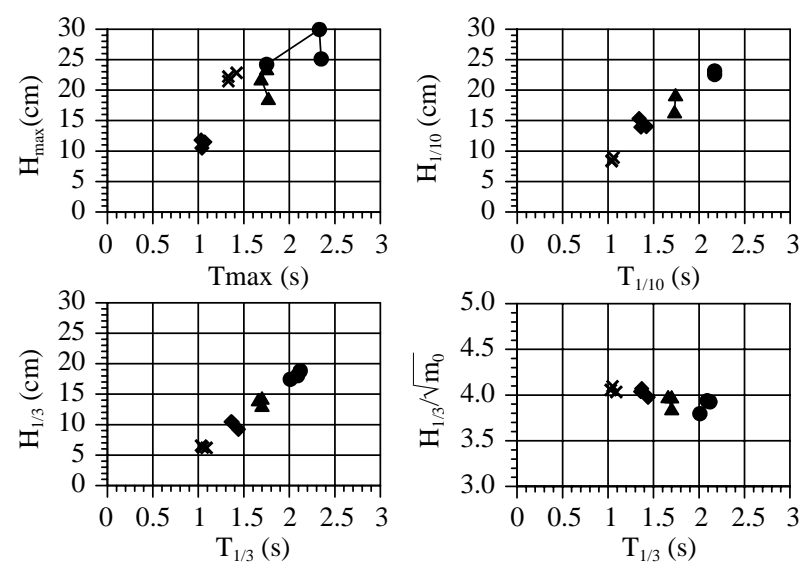

(•: JH25T20; • : JH19T16; : JH13T13; ×: JH08T10)

Fig. 15. Characteristic progressive wave heights/periods at the location of the breakwater.
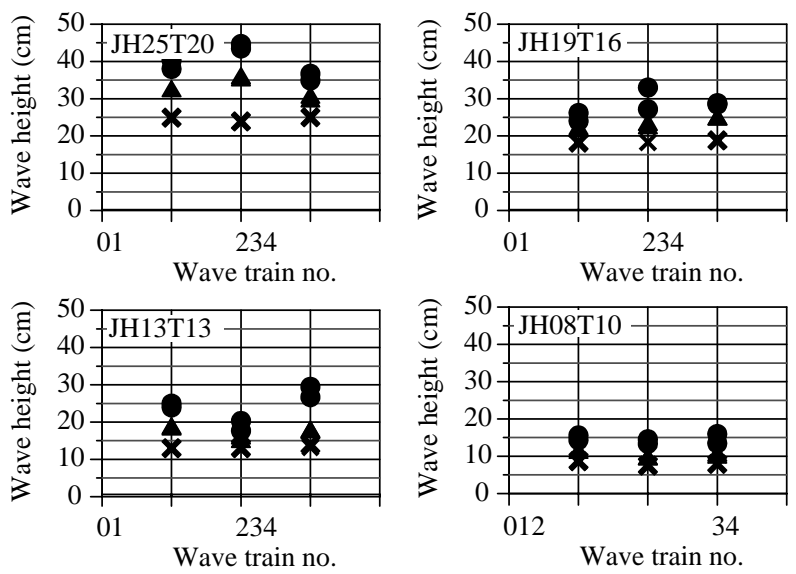

(•: $\mathrm{H}_{\max } \bullet: \mathrm{H}_{1 / 10} \times: \mathrm{H}_{1 / 3}$ )

Fig. 16. Characteristic standing wave heights/periods in front of the caisson.

tigations point out the uncertainty of the irregular wave test results, and should not be tested with only one wave train with several repeats.

\section{DISCUSSIONS}

\section{Comparisons of regular wave forces and irregular wave forces}

In order to compare the results of regular waves and irregular waves, Figure 17 presents the wave pressure distributions on vertical wall and at the bottom for all wave cases. Each figure contains the results of three irregular wave trains with two repeats (in symbols) and the distribution of maximum regular wave pressure (in solid line). For horizontal and uplift wave pressure distributions, the regular wave pressures are found close to the maximum irregular wave pressures in H08T10 and JH08T10 cases, close to highest 1/10 irregular wave 

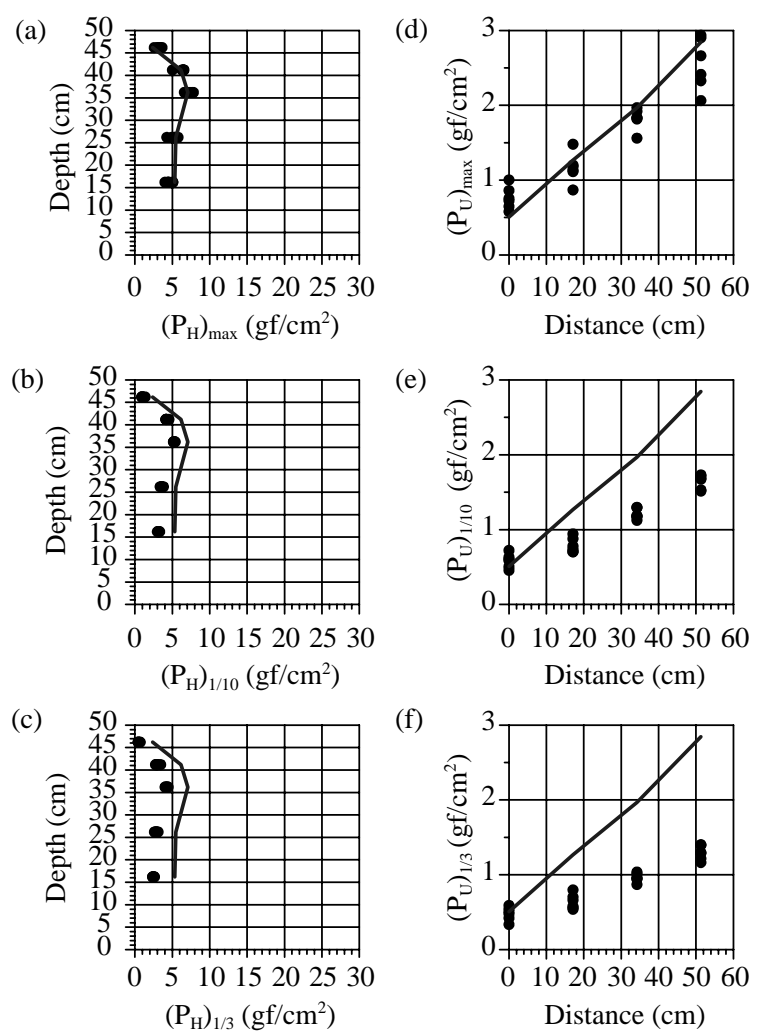

(e)

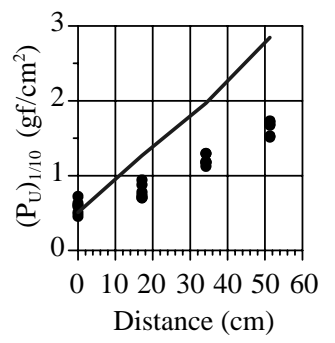

(f)

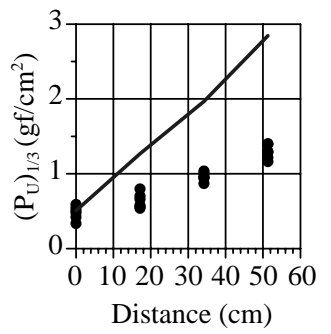

Cases H08T10 vs. JH08T10
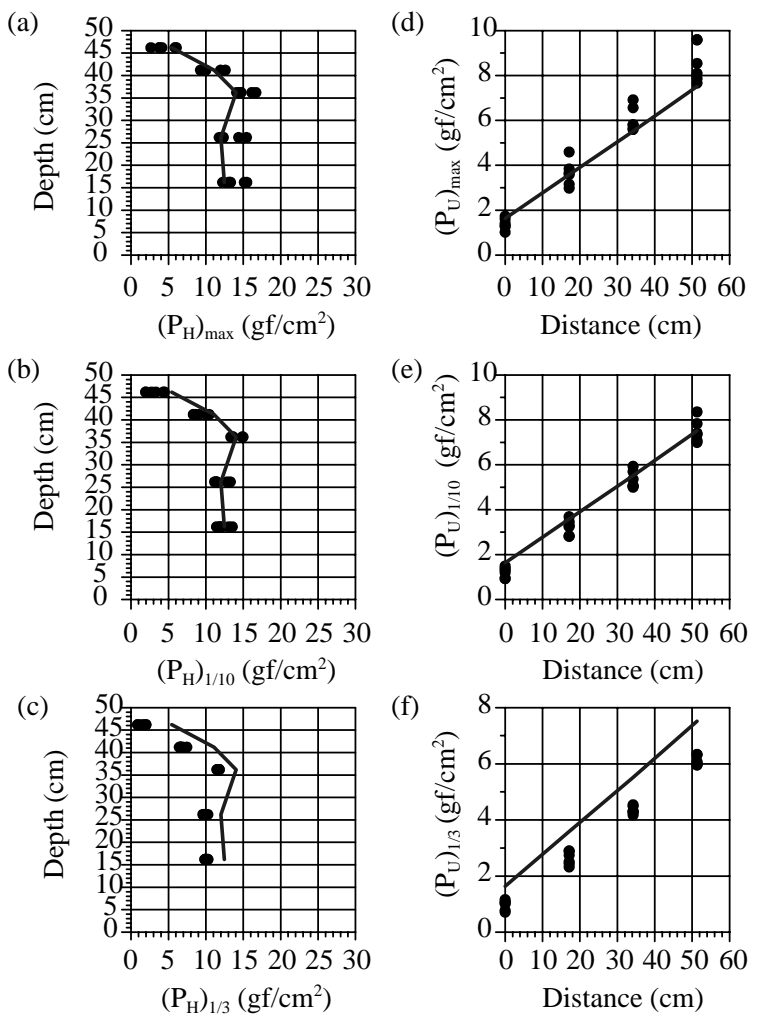

Cases H19T16 vs. JH19T16 (a)

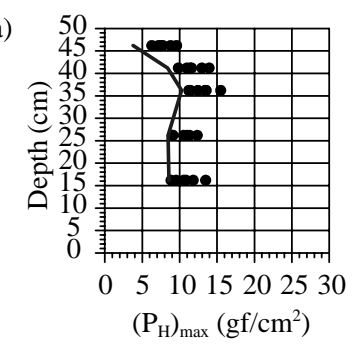

(b)

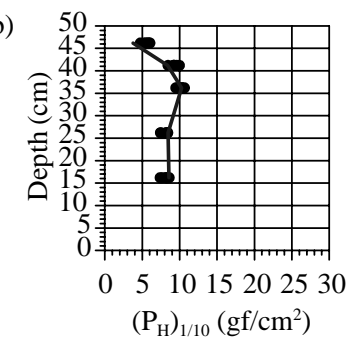

(c)

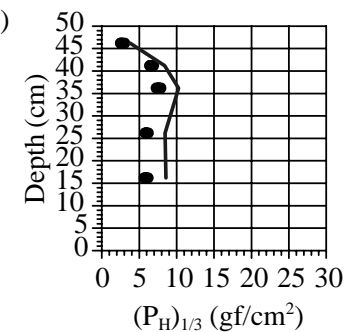

(d)

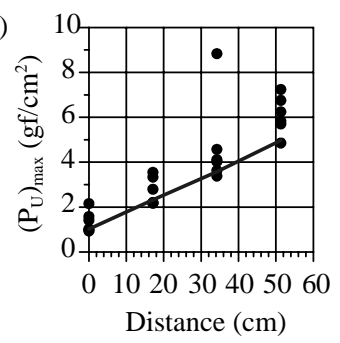

(e)

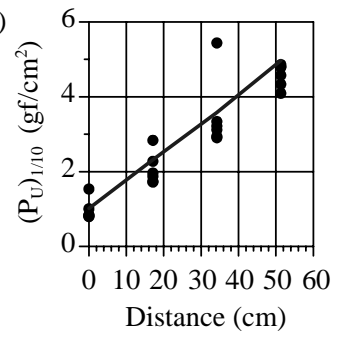

(f)

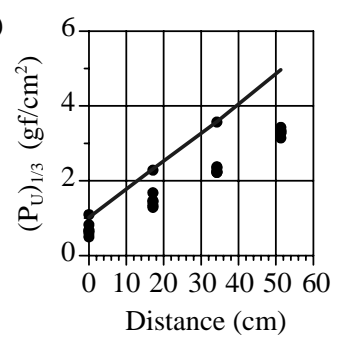

(a)

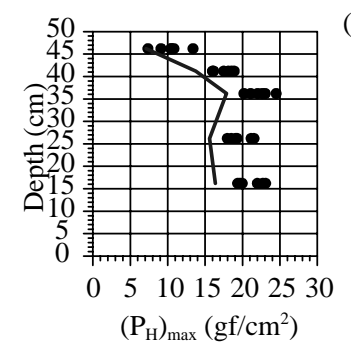

(b)

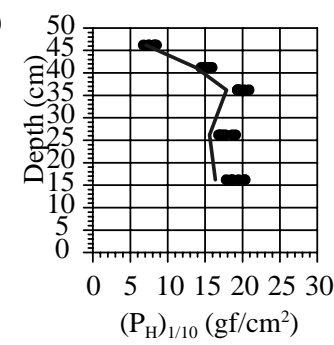

(c)

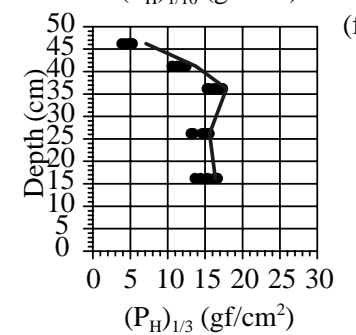

(d)

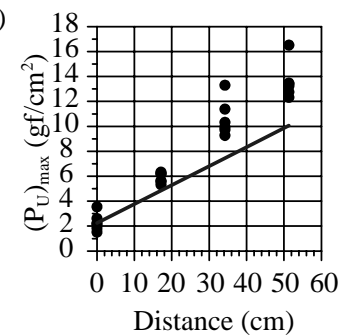

(e)

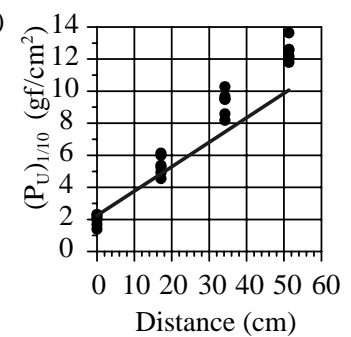

(f)

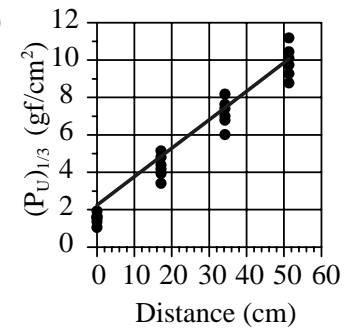

Cases H25T20 vs. JH25T20

Fig. 17. Comparisons of regular wave forces (solid line) and irregular wave forces (symbols) (a) maximum horizontal force; (b) highest $1 / 10$ horizontal force; (c) highest 1/3 horizontal force; (d) maximum uplift force; (e) highest 1/10 uplift force; (f) highest 1/3 uplift force. 
pressures in H13T13 and JH13T13 cases and in H19T16 and JH19T16 cases, but only close to highest $1 / 3$ irregular wave pressures in H25T20 and JH25T20 cases.

With these comparisons, one can see that the regular wave test for the wave forces acting on compositetype breakwater might be under-estimated. As a conclusion of this section, on evaluating the wave force acting on a coastal structure by means of hydraulic model test, irregular wave tests with different wave train of the same spectrum is a much proper way.

\section{Comparisons of theoretical wave forces and irregular wave forces}

In this section, the irregular wave pressure distributions are compared to Goda's wave force theories. Figures 18 to 21 present the horizontal and uplift wave pressure distributions of all wave cases. Each figure contains three wave trains with two repeats, and the experimental maximum $\left(\mathrm{P}_{\max }\right)$, highest $1 / 10\left(\mathrm{P}_{1 / 10}\right)$, highest $1 / 3\left(\mathrm{P}_{1 / 3}\right)$, and averaged $\left(\mathrm{P}_{\text {mean }}\right)$ pressures are com-
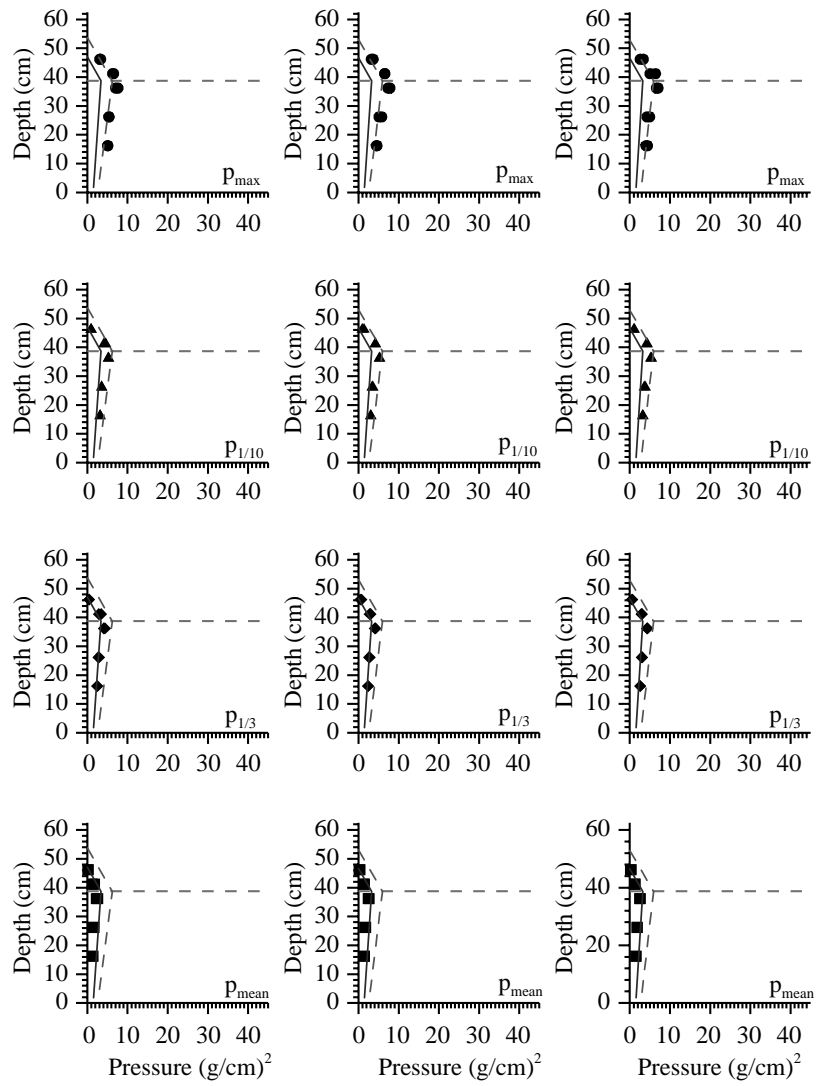

(a) Wave train 1
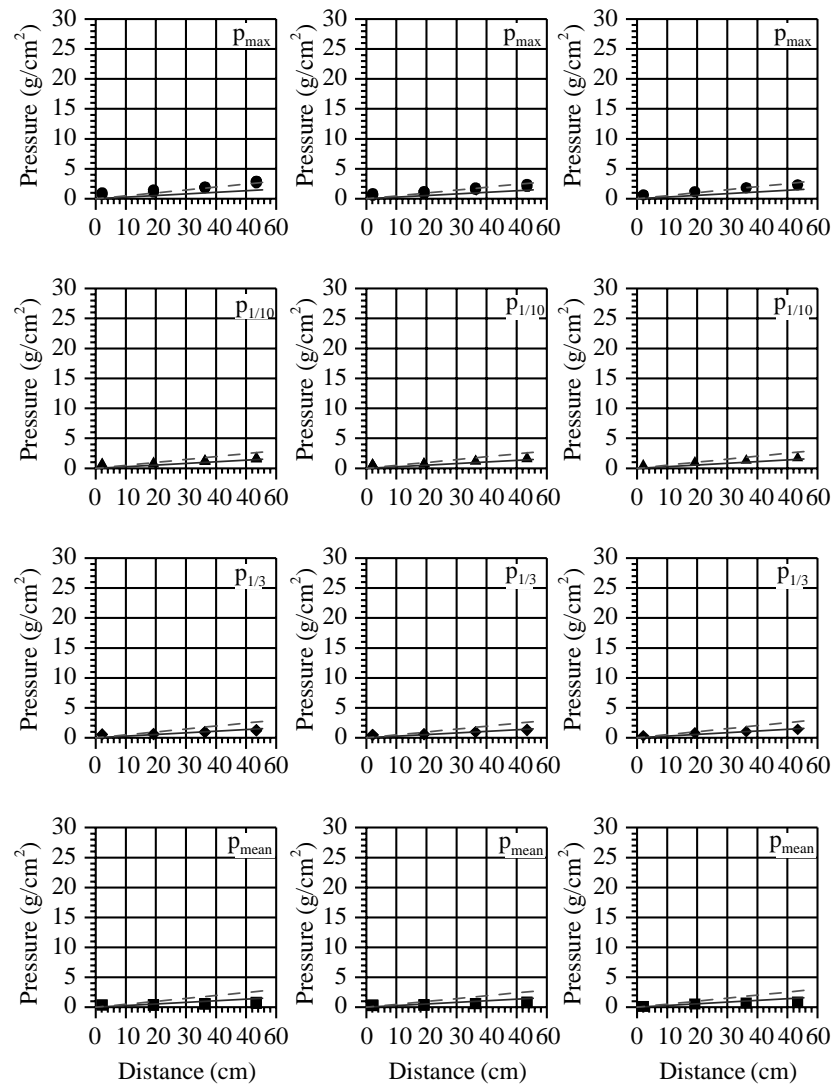

(a) Wave train 1

(b) Wave train 2

(c) Wave train 3

Horizontal pressures

Fig. 18. Comparisons of theoretical/irregular wave forces in Case $\mathrm{H08T10}$ (solid line: theoretical $\mathrm{H}_{1 / 3}$; dashed line: $1.8 \mathrm{H}_{1 / 3}$; solid symbol: experimental data). 

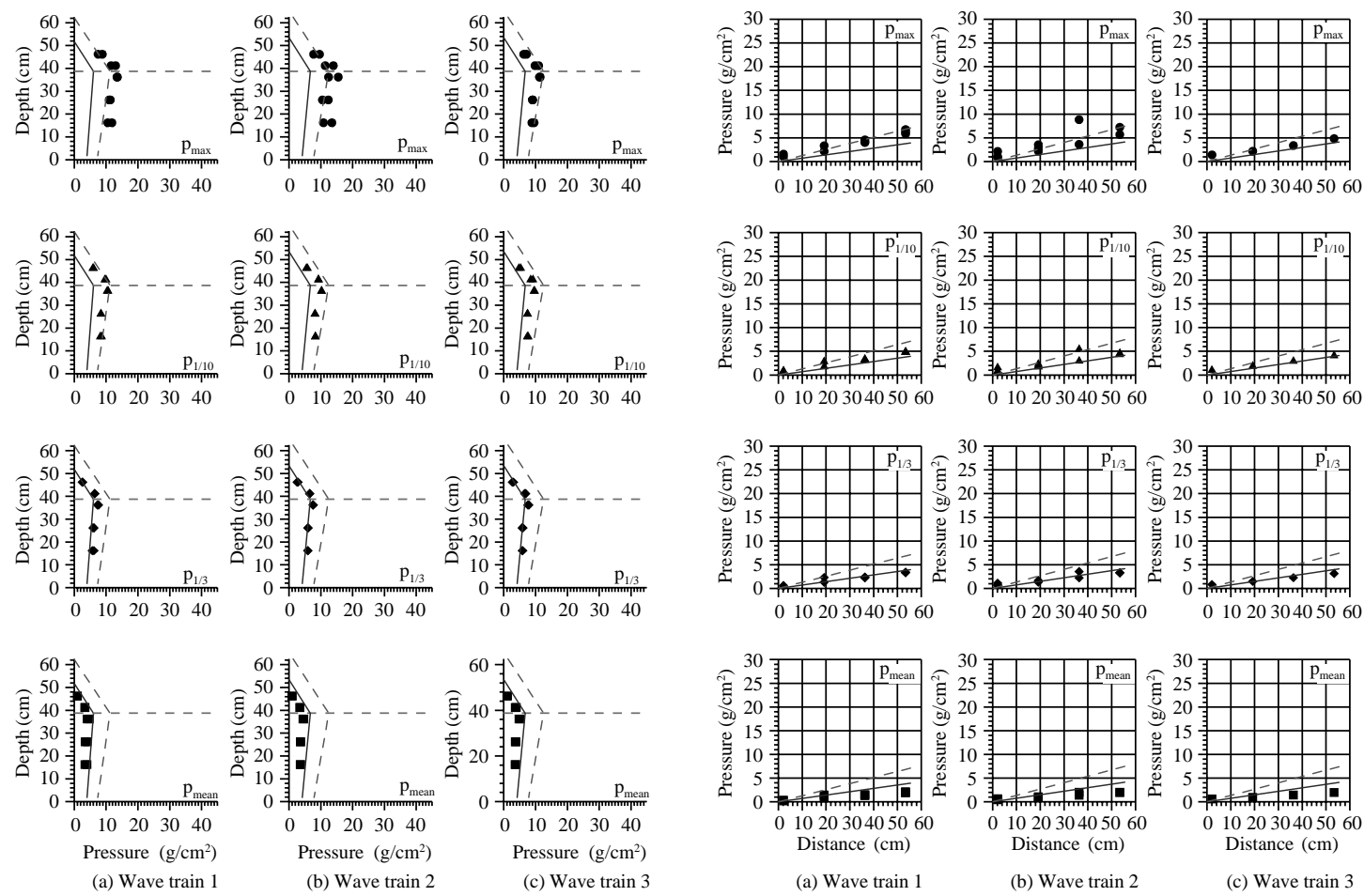

Horizontal pressures
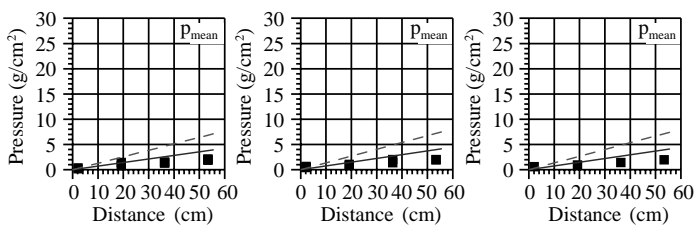

(a) Wave train 1

(c) Wave train 3

Fig. 19. Comparisons of theoretical/irregular wave forces in Case $\mathrm{H13T13}$ (solid line: theoretical $\mathrm{H}_{1 / 3}$; dashed line: $1.8 \mathrm{H}_{1 / 3}$; solid symbol: experimental data).
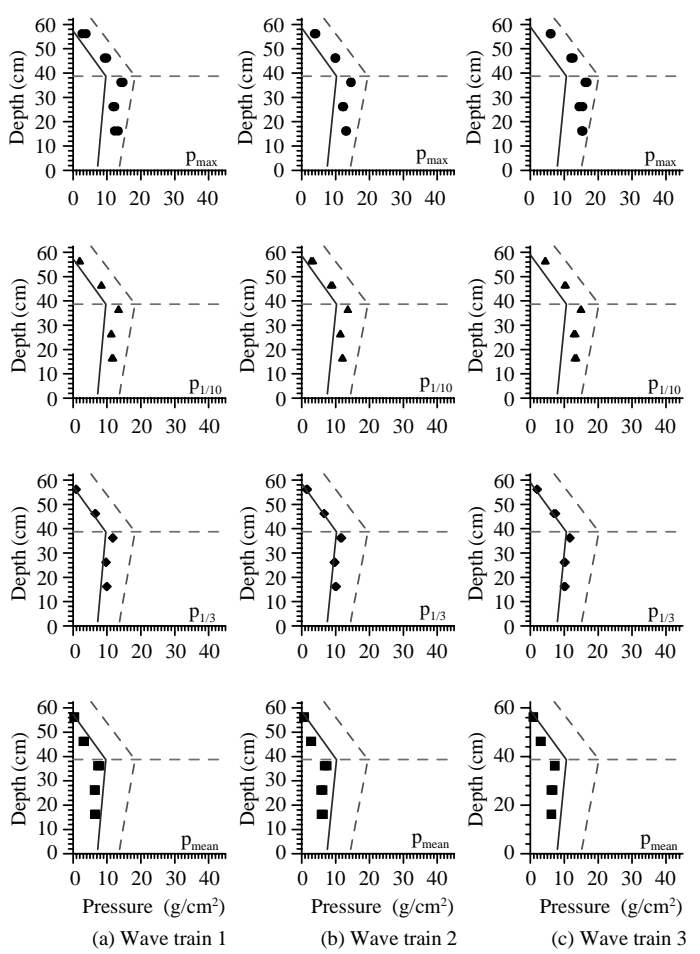

Horizontal pressures
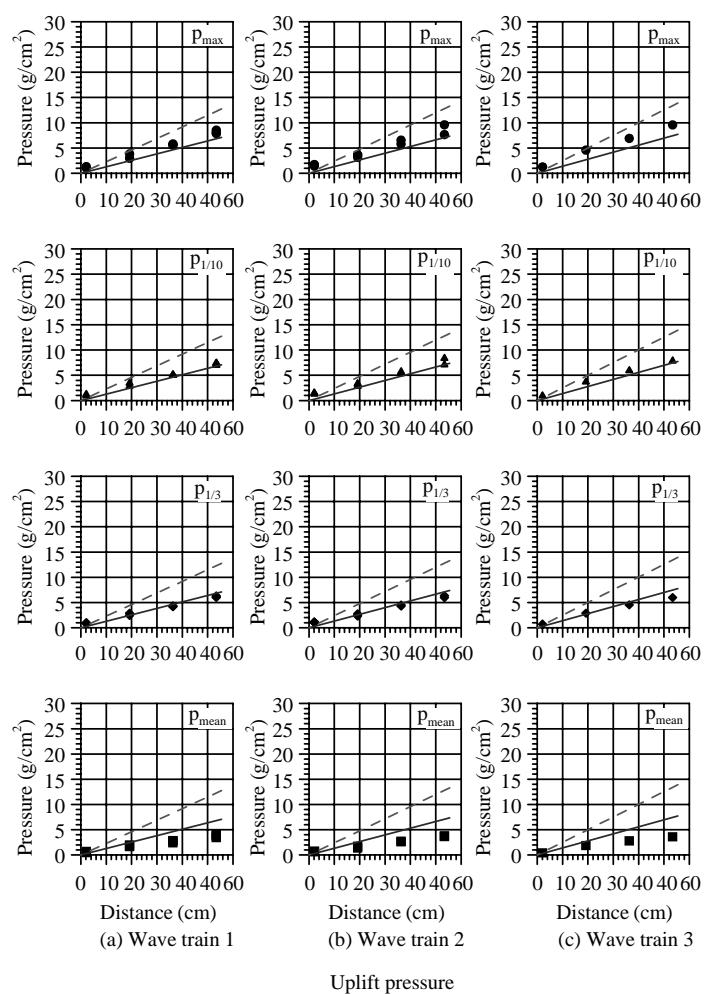

Uplift pressure

Fig. 20. Comparisons of theoretical/irregular wave forces in Case $\mathrm{H}_{19 T 16}$ (solid line: theoretical $\mathrm{H}_{1 / 3}$; dashed line: $1.8 \mathrm{H}_{1 / 3}$; solid symbol: experimental data). 

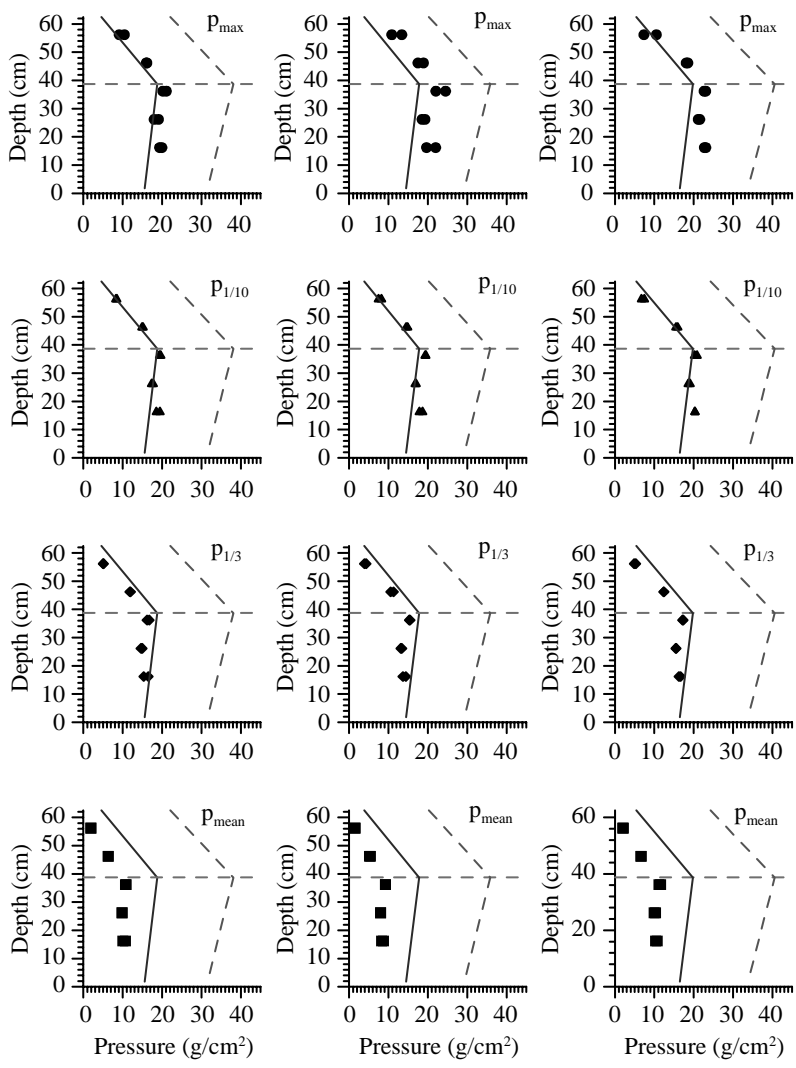

(a) Wave train 1

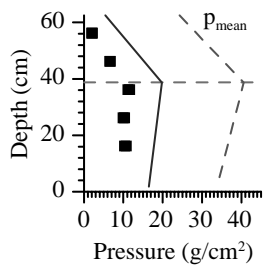

(c) Wave train 3
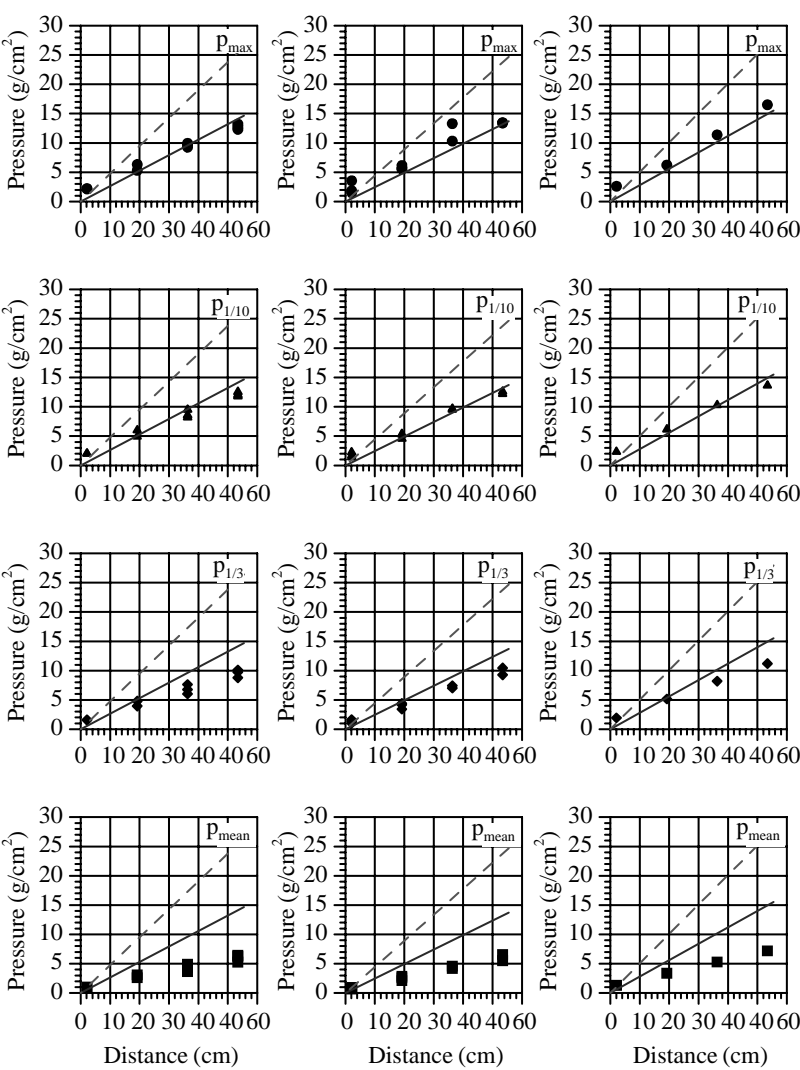

(a) Wave train 1

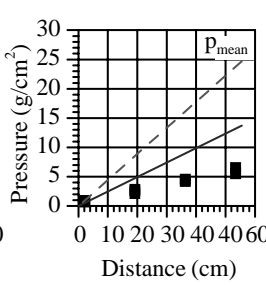

(b) Wave train 2

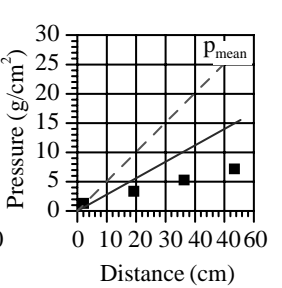

(c) Wave train 3

Horizontal pressures

Uplift pressure

Fig. 21. Comparisons of theoretical/irregular wave forces in Case $\mathrm{H}_{25 T 20}$ (solid line: theoretical $\mathrm{H}_{1 / 3}$; dashed line: $1.8 \mathrm{H}_{1 / 3}$; solid symbol: experimental data).

nearshore sloping bathymetry, the wave nonlinearity will become dominant. However, as wave pressures transmit into the porous media of seabed, their nonlinearities might be decayed, and approach to linear as depth increased.

2 . The occurrence times of maximum/minimum horizontal and uplift forces are not consistent with the arrival of wave crest/trough. But the total forces have only slightly difference in our cases. Wave forces at wave crest action with a proper safety factor are suggested.

3. Regular wave test underestimate the wave force acting on vertical breakwater, irregular wave test was suggested.

4. Wave forces will be increased as wave height/period increased. However, Goda's wave force theories underestimate the wave forces acting on caisson in small wave condition, and overestimate in large wave condition. As mention above, such phenomenon might be caused by the random property of waves and of the interactions among waves, sandy seabed, rubber mound foundation and breakwater.
5. Due to the randomness and uncertainty of the results, the irregular wave tests should not be tested with only one wave train and repeated several times. Optimal number of wave trains with the same spectrum but different component wave phases, and their statistical interpretations should be investigated further.

\section{REFERENCES}

1. Chen, C.-H., "Dynamic Behavior of Vertical Breakwater Induced by Irregular Waves," Master Theses, Department of Harbor and River Engineering, National Taiwan Ocean University (2004).

2. Goda, Y., Random Seas and Design of Maritime Structures, World Scientific, Singapore (1985).

3. Goda, Y., Technical Standards and Commentaries for Port and Harbour Facilities in Japan, The Overseas Coastal Area Development Institute of Japan, Japan (2002).

4. Hattori, M., Arami, A., and Yui, T., "Wave Impact Pressure on Vertical Wall under Breaking Waves of Various Types," Coastal Engineering, Vol. 22, pp. 79114 (1994). 
5. Klammer, P., "Oscillatory Motions and Permanent Displacements of Caisson Breakwaters Subject to Impulsive Breaking Wave Loads," Proceedings of the $24^{\text {th }}$ International Conference on Coastal Engineering, Venice ASCE, Vol. 2, pp. 1255-1268 (1996).

6. Kortenhaus, A. and Oumeraci, H., "Classification of Wave Loading on Monolithic Coastal Structure," Proceedings of the $26^{\text {th }}$ International Conference on Coastal Engineering, Venice ASCE, Vol. 1, pp. 867-880 (1998).

7. Lin, Y.-J., "Dynamic Behavior of Vertical Breakwater Induced by Regular Waves," Master Theses, Department of Harbor and River Engineering, National Taiwan Ocean University (2004).

8. Oumeraci, H., "Review and Analysis of Vertical Breakwater Failures- Lessons Learned," Coastal Engineering, Vol. 22, pp. 3-29 (1994).

9. Oumeraci, H. and Kortenhaus, A., "Analysis of the Dynamic Response of Caisson Breakwaters," (Special Issue on Vertical Breakwaters), Coastal Engineering, Vol. 22, pp. 159-183 (1994).
10. Oumeraci, H., Kortenhaus, A., and Klammer, P., "Displacement of Caisson Breakwaters Induced by Breaking Wave Impacts," Proceedings of the International Conference of the Institute of Civil Engineers Advanced in Coastal Structures and Breakwaters, London, UK, pp. 50-63 (1996).

11. Oumeraci, H., Partenscky, H.W., Kohlhase, S., and Klammer, P., "Impact Loading and Dynamic Response of Caisson Breakewater-Results of Large-Scale Model Tests," Proceedings of 23rd International Conference on Coastal Engineering, Venice, ASCE, Vol. 2, pp. 1475-1488 (1992).

12. Schmidit, R., Oumeraci, H., and Partenscky, H.-W., "Impact Loads Induced by Plunging Breakers on Vertical Structure," Proceedings of the $23^{\text {th }}$ International Conference on Coastal Engineering, Venice, ASCE, Vol. 2, pp. 1545-1558 (1992).

13. U.S Army Corps of Engineers, Coastal Engineering Manual, Coastal Engineering Research Center, USA (2002). 